\title{
Duas espécies novas de Macrophyllodromia do Estado do Acre, Brasil (Blattaria, Blattellidae) coletadas em ninhos de vespas
}

\author{
Sonia Maria Lopes \& Edivar Heeren de Oliveira
}

Departamento de Entomologia, Museu Nacional, Universidade Federal do Rio de Janeiro, Quinta da Boa Vista, São Cristóvão, 20940040 Rio de Janeiro, RJ, Brasil. (sonialf@acd.ufrj.br)

\begin{abstract}
Two new species of Macrophyllodromia from Acre State, Brazil (Blattaria: Blattellidae) collected in wasps nests. Macrophyllodromia lanceolata sp. nov. and M. multipunctata sp. nov. are described from Acre State (Brazil) based on a specimens collected in a wasps nests. Illustrations of the male genitalia are presented. Macrophyllodromia is newly recorded for Brazil.
\end{abstract}

KEYWORDS. Blattaria, Macrophyllodromia lanceolata sp. nov., Macrophyllodromia multipunctata sp. nov., wasps nests, Neotropical.

RESUMO. Macrophyllodromia lanceolata sp. nov. e M. multipunctata sp. nov. são descritas do Estado do Acre (Brasil), com base em espécimens coletados em ninhos de vespas. São apresentadas ilustrações da genitália do macho e o novo registro do gênero no Brasil.

PALAVRAS-CHAVE. Blattaria, Macrophyllodromia lanceolata sp. nov., Macrophyllodromia multipunctata sp. nov., ninhos de vespas, Neotropical.

Macrophyllodromia Saussure \& Zehntner,1893 é um gênero neotropical similar a Blattella Caudell, 1839 quanto ao caráter das duas listras longitudinais castanhoescuras no pronoto, diferindo deste pelo maior porte; também é semelhante a Latiblattella Hebard, 1917, Antitheton Hebard, 1919 e Eurylestes Hebard, 1940, diferenciando pelo: 1) grande porte entre os blatelídeos; 2) espaço interocular mais estreito que a área entre a base das antenas; 3) cabeça com uma mancha escura que se estende da área interocular até a sutura do labro, e palpos maxilares bem desenvolvidos; 4) pronoto convexo lateralmente; 5) tégminas e asas desenvolvidas, os ramos da mediana e cubital (campo discoidal) oblíquos nas tégminas; 6) asas com ramo anterior não dilatado apicalmente e triângulo intercalar pequeno; 7) abdome sem modificação tergal; 8) placa supra-anal transversa e projetada entre os cercos, com ápice arredondado. Placa subgenital assimétrica e supra-anal da fêmea convergente para o ápice, arredondada. Placa subgenital com as margens amplamente convexas e arredondadas. Fêmur anterior com margem ântero-ventral com uma série de espinhos grandes, que decrescem gradativamente em tamanho próximo à região médio-apical do fêmur, e três maiores apicais. Pulvilos e arólios moderadamente desenvolvidos. Unhas tarsais simples.

Rocha e Silva-Albuquerque (1962) assinalou para o gênero cinco espécies que são distribuídas nas Guianas, Honduras, Panamá, Guatemala e México. A espécie-tipo é Pseudophyllodromia maximiliani Saussure, 1873, descrita do México.

Com base na configuração das placas genitais (supra-anal e subgenital) do macho, bem como do L2vm, R2 e L1, verificou-se tratar de dois novos táxons de Macrophyllodromia, gênero registrado pela primeira vez no Brasil, e que são descritos neste trabalho. As duas espécies foram coletadas servindo de alimento a vespas do gênero Podium Fabricius, 1804, um himenóptero da família Sphecidae.

\section{MATERIAL E MÉTODOS}

Os espécimes foram analisados de acordo com as técnicas utilizadas e descritas em LOPES \& OLIVEIRA (2000) e estão depositados na coleção do Departamento de Entomologia do Museu Nacional, Universidade Federal do Rio de Janeiro (MNRJ).

A designação das peças genitais foi baseada nos conceitos propostos por MCKITTRICK (1964).

\section{Macrophyllodromia lanceolata sp. nov. (Figs. 1,3-5, 9,12-14)}

Descrição. Coloração geral castanha. Pronoto castanho-claro com alguns pontos esparsos castanhos mais escuros; disco central castanho-escuro com pequena mancha castanho-clara centro-mediana (Fig. 3). Cabeça com vértice castanho-amarelado; olhos negros; fronte castanho-escura (Fig. 1); antenas e ápice dos palpos maxilares castanho-claros. Tégmina com o tronco inicial de todas as nervuras castanho-escuro, campo marginal mais claro. Pernas com a base de inserção dos espinhos castanho-escura; pulvilos e arólios esbranquiçados.

Cabeça triangular, vértice exposto, espaço interocular pouco amplo, com cerca de um terço da área que separa a base das inserções antenais. Antenas longas, ultrapassando o ápice do abdome, filiformes e cerdosas. Palpos maxilares com terceiro artículo pouco maior que o quarto; quinto artículo dilatado, cerdoso e menor que os anteriores.

Tórax com pronoto oval e transverso, com ápice 

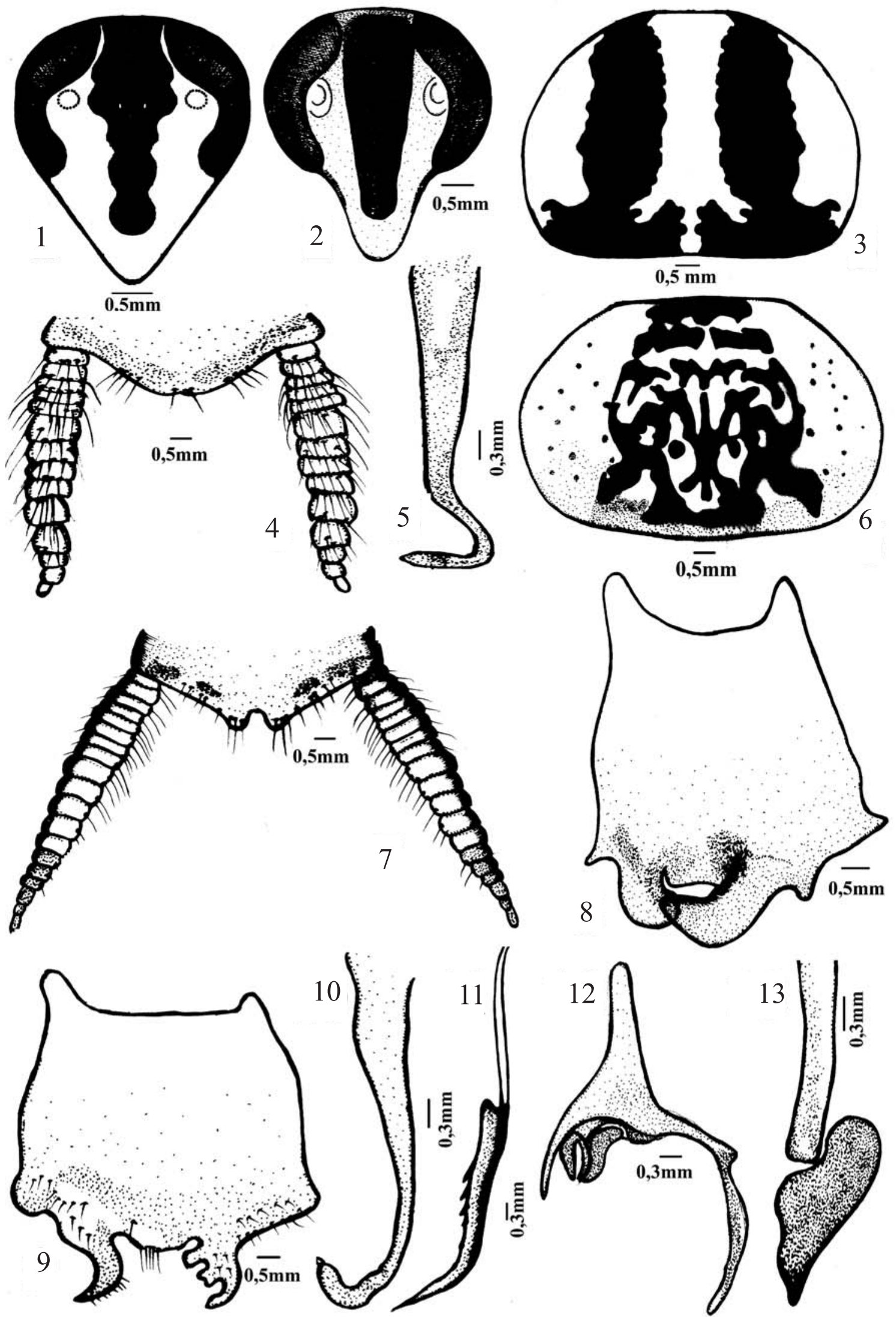

Figs. 1-13. Macrophyllodromia lanceolata sp. nov., ơ: 1, cabeça, frontal; 3, pronoto, dorsal; 4, placa supra-anal, dorsal; 5, falômero direito (R2), dorsal; 9, placa subgenital, ventral; 12, falômero esquerdo (L1), dorsal; 13, esclerito mediano (L2vm), dorsal. Macrophyllodromia multipunctata sp. nov, o: 2, cabeça, frontal; 6, pronoto, dorsal; 7, placa supra-anal, dorsal; 8, placa subgenital, ventral; 10, falômero direito (R2), dorsal; 11, esclerito mediano (L2vm), dorsal. 
reto e entorno lateral arredondado; disco central circular, abas laterais amplas. Tégminas desenvolvidas, longas, ultrapassando o ápice dos cercos (Fig. 14). Campo marginal levemente côncavo, bem marcado, subcostal sinuosa e bifurcada próximo ao ápice; campo escapular convexo e reto; campo discoidal curvo no ápice da tégmina e reto próximo ao campo anal, apresentando nove a dez nervuras bem evidentes. Pernas desenvolvidas e espinhosas. Face ântero-ventral do fêmur I com uma série de espinhos que decrescem gradativamente em tamanho da base em direção à região mediana, retomando levemente o crescimento em direção ao ápice, terminando em três espinhos apicais desenvolvidos; face pósteroventral com quatro espinhos espaçados e um apical. Fêmures II e III com espinhos esparsos, com distribuição semelhante nas faces ântero- e póstero-ventrais. Pulvilos em todos os artículos tarsais; arólios desenvolvidos, menores que as unhas, estas simples e simétricas.

Abdome o com placa supra-anal cerdosa, triangulóide, estreita, simples, com reentrância medianoapical quase imperceptível; cercos cerdosos e desenvolvidos (Fig. 4). Placa subgenital quadrangular, assimétrica, com pequena proeminência arredondada e cerdosa médio-apicalmente entre os estilos; estilos diferenciados (Fig. 9). Na genitália, falômero esquerdo (L1) afilado com prolongamentos diferenciados e estrutura esclerotinizada pouco desenvolvida medianamente (Fig. 12). Falômero direito (R2) em forma de gancho (Fig. 5). Esclerito mediano (L2vm) com ápice (L2d) em forma foliácea e bastante esclerotinizada (Fig. 13).

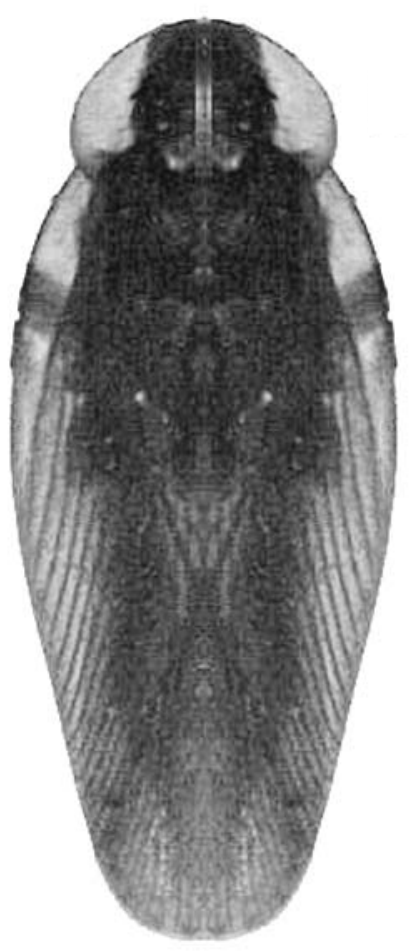

14
Medidas em mm, o. Comprimento total, 23,0; comprimento do pronoto, 4,5; largura do pronoto, 6,5; comprimento da tégmina, 20,0; largura da tégmina, 5,5.

Material-tipo. Holótipo $\overparen{\sigma}$, BRASIL, Acre: Senador Guiomard (Reserva Catuaba), 104'S, 67³6'W, 16.X.2001, Elder F. Morato col. (ninho 572/1). Parátipos ơ, mesma localidade do holótipo: 04.VII.2001, (ninho 60/1); 03.VIII.2001, (ninho 181/ 3); 19.VIII.2001, (ninho 272/3); (ninho 296/1); (ninho 347/1); (ninho 396/1); (ninho 337); todos em ninhos de vespas Sphecidae, Podium sp.

Etimologia. Nome alusivo à configuração do L2vm na genitália do macho.

Diagnose. A espécie é distinta entre as demais do gênero pela coloração da cabeça e pronoto e pela configuração das placas genitais e genitália do macho.

\section{Macrophyllodromia multipunctata sp. nov. (Figs. 2, 6-8, 10, 11, 15)}

Descrição. Coloração geral castanho-amarelada. Pronoto com borda castanho-escura, disco central com manchas amarelas sem forma definida; abas laterais amplas, com pontos dispersos castanho-escuros (Fig. 6). Cabeça com vértice exposto, castanho-escuro; olhos negros; fronte com faixa longitudinal castanho-escura quase negra do vértice até a altura do clípeo, este castanho (Fig. 2); genas castanho-escuras. Antenas castanhas. Tégmina com faixas longitudinais castanhas cobrindo as nervuras, mais marcadas na região do campo anal. Pernas com o dorso dos fêmures e o ápice dos tarsos castanho-escuros.

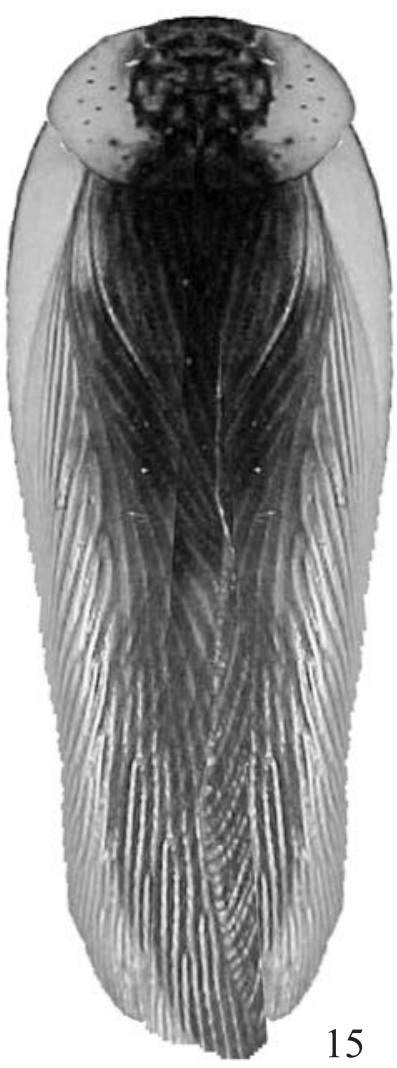

Figs. 14-15. Habitus de Macrophyllodromia: 14, M. lanceolata sp. nov., §’, comprimento 23 mm; 15, M. multipunctata sp. nov., ऊ', comprimento $24 \mathrm{~mm}$. 
Cabeça triangular, vértice exposto. Espaço interocular amplo, com cerca da metade da área que separa as bases das inserções antenais; antenas longas, filiformes e tomentosas. Palpos maxilares bem desenvolvidos e tomentosos, terceiro e quarto artículos iguais em tamanho e maiores que o quinto, este bastante dilatado próximo à base e gradativamente afilado para o ápice.

Tórax com pronoto oval, curto e alargado, com ápice reto e entorno lateral arredondado. Disco central circular, abas laterais amplas. Tégminas desenvolvidas, longas, ultrapassando o ápice dos cercos (Fig. 15). Campo marginal levemente côncavo, bem marcado, subcostal sinuosa e bifurcada próximo ao ápice; campo escapular convexo e reto; campo discoidal curvo no ápice da tégmina e reto próximo ao campo anal, apresentando nove a dez nervuras bem evidentes. Pernas longas e espinhosas. Fêmur I, na face ântero-ventral, com uma série de espinhos que decrescem gradativamente em tamanho da base até a região mediana, retomando levemente o crescimento em direção ao ápice, que possui três espinhos desenvolvidos. Fêmures II e III com seis a oito espinhos médios em tamanho, dispostos espaçadamente da base ao ápice, semelhantes nas faces ântero- e pósteroventrais. Unhas simétricas, bem desenvolvidas, sem especialização; pulvilos em todos os artículos tarsais; arólios desenvolvidos.

Abdome do o com placa supra-anal triangular, simétrica, estreita e bilobada na região médio-apical (Fig. 7). Placa subgenital quadrangular, assimétrica, apresentando no bordo látero-apical proeminências agudas; estilos irregulares em forma e tamanho, alargados e voltados para o interior da placa (Fig. 8). Na genitália, falômero direito (R2) afilado em forma de gancho (Fig. 10). Esclerito mediano (L2vm) alongado com ápice (L2d) esclerotinizado, afilado e pontiagudo, e o bordo interno serrilhado (Fig. 11).

Medidas em mm, or. Comprimento total, 24,0; comprimento do pronoto, 5,0; largura do pronoto, 7,0; comprimento da tégmina, 21,0; largura da tégmina, 7,0.

Material-tipo. Holótipo ơ, BRASIL, Acre: Senador Guiomard (Reserva Catuaba), 10²'S, 67³6’W, 02.X.2001, E. F. Morato col. (ninho 524/2).

Etimologia. Nome alusivo às manchas distribuídas em volta do disco central no pronoto.

Diagnose. A espécie é distinta das demais pela coloração da cabeça e pronoto, e pela configuração das placas genitais e genitália do macho.

Agradecimentos. Ao Dr. Elder F. Morato, da Universidade Federal de Minas Gerais, pelo material coletado.

\section{REFERÊNCIAS BIBLIOGRÁFICAS}

Lopes, S. M. \& Oliveira, E. H. 2000. Espécie nova de Eublaberus Hebard, 1919 do Estado de Goiás, Brasil e notas sobre E. marajoara Rocha e Silva-Albuquerque, 1972 (Blaberidae, Blaberinae). Boletim do Museu Nacional, Nova Série, Zoologia, 433:1-5.

Mckittrick, F. A. 1964. Evolutionary studies of cockroaches. Cornell Experiment Station Memoir 389:1-197.

Rocha E Silva-Albuquerque, I. 1962. Synopsis of the Neotropical cockroach genus Macrophyllodromia (Orthoptera: Blattoidea, Epilampridae). Proceedings of the United States National Museum 3461(113):421-428. 